\title{
Forgotten Ureteral Stents in a Tertiary Hospital in Accra and a Review of Endourological Management of Upper Urinary Tract Pathologies in the West Africa Sub-Region
}

\author{
Lemuel Davies Bray, Mathew Yamoah Kyei, James Edward Mensah, \\ Kwadwo Ntiamoah Ampadu, Isaac Obeng Asiedu, Bernard Toboh, Evans Akpakli, \\ Foli Ashiagbor, Joseph Awuku-Asabre, Mawuenyo Oyortey \\ Department of Surgery and Urology, School of Medicine and Dentistry, College of Health Sciences, University \\ of Ghana, Accra, Ghana \\ Email: atobray@yahoo.com
}

Received 10 April 2016; accepted 14 June 2016; published 17 June 2016

Copyright (C) 2016 by authors and Scientific Research Publishing Inc.

This work is licensed under the Creative Commons Attribution International License (CC BY). http://creativecommons.org/licenses/by/4.0/

(c) (i) Open Access

\begin{abstract}
Background: Forgotten ureteral stent is defined as prolong indwelling ureteral stent whose function is no longer desired. Ureteral stents are used in the management of upper urinary tract pathologies. Prolonged indwelling ureteral stents may be complicated by urosepsis or renal failure, encrustation, stone formation, spontaneous fracture which may either be retained or voided in the urine (stenturia). Hitherto, these complications were managed by open procedures alone in our center. We report our recent experience in endourology with the management of three cases of forgotten ureteral stents with durations of ten years and two years (two cases) and review endourological practice in West Africa. Conclusion: Although encrusted stents can be managed successfully by minimally invasive approaches in the majority of cases, the best treatment is prevention. Urology units should have preferably an electronic stent register such that when the time for removal is due, the patient's name and details are flagged red. If electronic register is not available, then a hard paper/book register should be made to prevent situations of forgotten stents. Also, efforts must be made to improve endourological services in the West Africa sub-region to allow patients to have the benefit of endourology in the management of upper urinary tract pathologies including that of stones originating from an encrusted or fractured forgotten ureteral stent.
\end{abstract}




\section{Keywords}

\section{Ureteral Stent, Encrustation, Endourology, West Africa}

\section{Introduction}

Since its description by Zimskind in 1967, ureteric stents have undergone modifications and have become a ubiquitous tool for the urologist. Although we have come a long way from the initial straight Zimskind silicone catheter with advances in anchoring devices, composition and coatings, we still strive to find the ideal stent [1].

Ureteral stent placement is an important adjunct to many urologic procedures. It may be used for the prevention or relief of upper urinary tract obstruction and following reconstructive surgery. Examples of such procedures include the management of renal or ureteral stones as in extracorporeal shock wave lithotripsy (ESWL), endoscopic (ureteroscopy, renoscopy) lithotripsy and open stone removal [2]. Ureteral stents are used for relieving hydronephrosis due to ureteral trauma or strictures, malignant neoplasm or retroperitoneal fibrosis [2]. Indwelling ureteral stents therefore need to be changed at regular periods to prevent complications. Various authors have reported indwelling time between 2 - 4 months as safe. The causes of forgotten ureteral stents could be classified as surgeon's, patient's, stent material and others factors [3]. Prolong urinary stasis, urinary tract infections (UTIs) especially by urease splitting organism, and dehydration promote biofilm (slippery slime) formation on the surface of the stent with subsequent crystalloid deposition [4]-[6]. Pregnancy and incarceration enhance ureteral encrustation as well [7]. Biochemical and optical analyses of stent encrustations by Robert et al. revealed that encrustations consisted mainly of calcium oxalate, calcium phosphate and ammonium magnesium phosphate [8]. Hard water consumption may perhaps promote stent encrustation due to the high content of calcium and magnesium carbonates; hence may necessitate early ureteral stent removal or change in such situations.

Encrustation, stone formation or fragmentation of indwelling ureteral stents can pose a formidable management challenge especially in resource-poor settings. Open surgeries are commonly performed for upper urinary tract pathologies in most West African countries because of lack of endourology equipment and expertise [9] and applied to management of encrusted ureteral stents as well.

We present three cases of encrusted forgotten/neglected ureteral stents with durations of ten years and two years (two cases) seen over a 10-year period and managed by endourologic procedures in two cases and a combination of endourology and open procedure in one case in our institution. We then proceeded to review the current practice of endourology in the West Africa sub-region.

Case 1: A 78-year old female with a year's history of intermittent right flank pains presented with a recurrence of the right flank pains, fever and chills. She had a past history of a similar but more severe right flank pains ten years ago and was hospitalized in a suburban General hospital in the United States of America (USA). She apparently had a right ureteric stent inserted for an obstructing right ureteric calculus and returned home (Ghana) one month after the procedure but denied knowledge of the indwelling ureteral stent. On further evaluation of the current symptoms, a Kidney, ureter and bladder (KUB) radiograph and abdomen and pelvis CT Scan done revealed a full length encrustation of a ureteral stent with heavy stone burden at the renal pelvis and bladder coils [most of the stone was radiolucent on KUB] (Figure 1(a)) and a non-obstructing multiple left renal calculi. Her urine analysis showed cloudy urine with blood (3+) and pus cells-14/phf. Urine culture isolated Escherichia coli which was sensitive to meropenem and nitrofurantoin. Her blood urea and creatinine levels were $6.6 \mathrm{mmol} / \mathrm{L}$ reference range $(2.0-7.0 \mathrm{mmol} / \mathrm{L})$ and $124 \mathrm{umol} / \mathrm{L}$ reference range $(62-106 \mathrm{mmol} / \mathrm{L})$ respectively. Subsequent to treating the associated urosepsis, the stent was retrieved in whole (Figure 1(c)) after two sections of ureteroscopy with alternating endoscopic ultrasonic and ballistic fragmentation of the stones. The first surgery lasted 2 hours 30 minutes and the second 1 hour 24 minutes at two week interval. Post procedure recovery was uneventful and she is being followed up for the non-obstructing left renal calculi.

Case 2: A 31-year old mechanic who had been attacked by armed robbers sustained multiple penetrating abdominal wounds from a close range gunshot to the abdomen. At surgery, in addition to multiple bowel perforations requiring intestinal resection and anastomosis, a mid-ureteric perforation seen was closed over a ureteral stent. He was discharged a week after the surgery. He got lost to follow up until he reported after two years with 


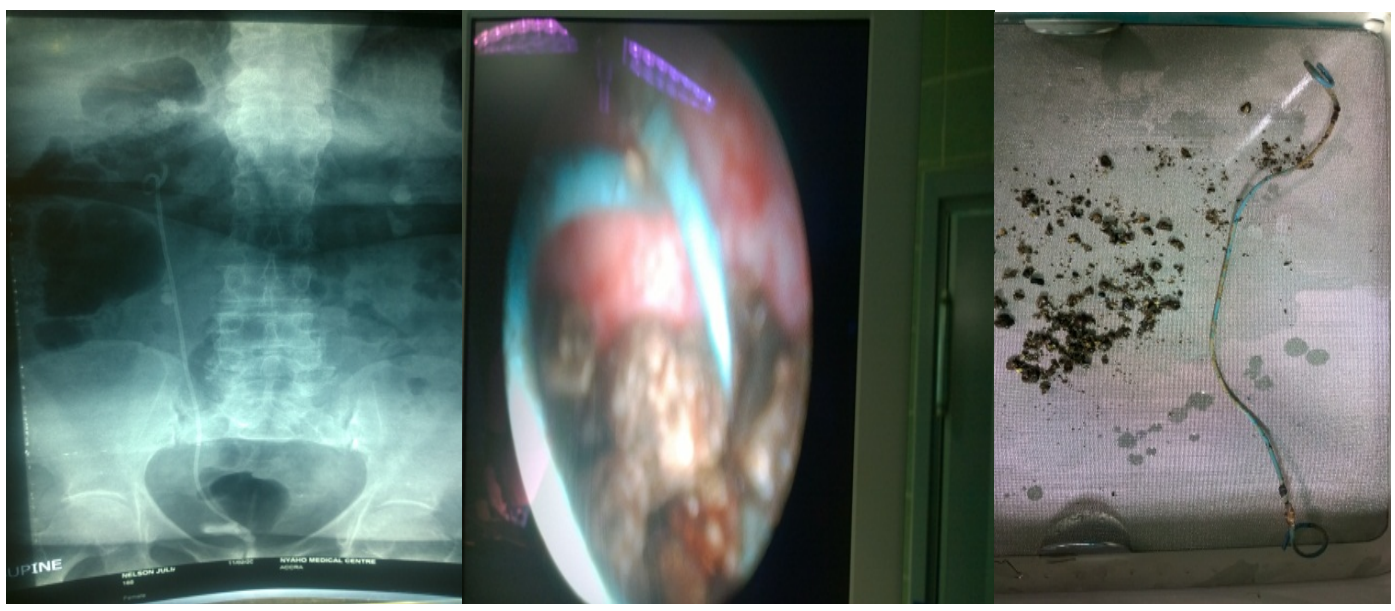

(a)

(b)

(c)

Figure 1. Images of encrusted ureteral stent in situ for 10 years. (a) KUB showing encrusted stent. (b) Endoscopic appearance of lower coil encrustation. (c) Retrieved stent with fragments.

recurrent dysuria, hematuria and having voided a piece of the stent material. He denied knowledge of an indwelling ureteral stent. A KUB done revealed a fractured indwelling right ureteric stent (Figure 2(a)). The distal fragment was removed using a rigid ureteroscope. A right open pyelolithotomy to retrieve the retained proximal stent was unsuccessful as it had migrated into one of the calyxes. The use of a flexible ureteroscope enabled visualization of the stent material and with laser, the encrusted impacted piece of stent was retrieved (Figure 2(b)).

Case 3: A 23-year old student nurse with a left single kidney (agenesis of right kidney in Figure 3(a)) was diagnosed with pyonephrosis due to a pelviureteric junction obstruction of the kidney. As part of her management, she had a ureteral stent placed (Figure 3(b)) to drain the pyonephrosis to improve the renal function which was deranged (blood urea $23.2 \mathrm{mmol} / \mathrm{l}$, reference range $(2.0-7.0 \mathrm{mmol} / \mathrm{L})$, creatinine $710 \mathrm{umol} / \mathrm{l}$, reference range (62 - $106 \mathrm{umol} / \mathrm{L}$ ), $\mathrm{Hb} 4.4 \mathrm{~g} / \mathrm{dl}$ ) reference range 11.0 - $18.0 \mathrm{~g} / \mathrm{dl}$. She eventually had open pyeloplasty with a ureteral stent placement. She was lost to follow up until two years after, when she appeared for review on account of a left flank pain. A diagnosis of a forgotten ureteral stent was made. Encrustations were minimal and the stent was removed in whole cystoscopically with gentle traction on the stent (Figure 3(c)).

\section{Discussion}

The incidence of forgotten ureteric stents and stent encrustation is unknown and there are hardly any reports from West Africa. Our report shows that 3 cases of forgotten stents were seen over a 10 year period making it an unusual occurrence despite the wide spread use of ureteral stents for upper urinary tract diseases and surgeries in the sub-region. The exact mechanism of encrustation is not clear. It however appears to be dependent on several factors. All patients denied knowledge of the presence of the ureteral stents in this series.

Stent material may contribute to encrustation. Silicone containing stents tend to be more resistant to encrustation, followed by polyurethane, silitek, percuflex and hydrogel coated polyurethane [1]. Studies have shown no encrustation on silicone containing stents at 10 to 12 months dwell time compared to $76 \%$ encrustation rate of polymer stents at 12 months [10] [11]. The ureteral stents we use in our center is made of polyurethane. The use of biodegradable stents which are made with high molecular weight polymers such as polyglycolide, polylactide and uriprene obviates the need for cystoscopic removal or change and thus, mitigating procedure related complications, cost, patient discomfort and stent neglect. Their complete dissolution and controllability of degradation rate however remains to be perfected [12]. The application of antifouling coatings to ureteral stents reduces bacterial adhesion and encrustation. Heparin coated stents have been shown to be effective at reducing stent encrustation [13]. Hydrogel coating is able to absorb water, forming a thin liquid layer in the surface of the stent and, thus, preventing bacterial adhesion while providing improved lubrication [14]. Metal stents, albeit expensive, have a longer dwell time and fewer stent change associated morbidities and are particularly suitable for 


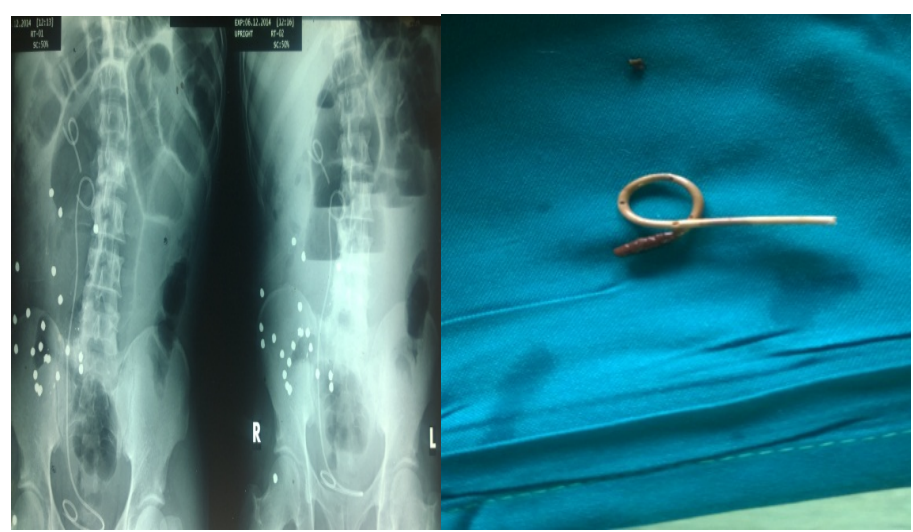

(a)

(b)

Figure 2. Images of fractured ureteral stent. (a) KUB-showing fractured stent and pellets with a new ureteral stent placed after unsuccessful open pyelolithotomy for stent fragment retrieval; (b) Retrieved fragmented stent.

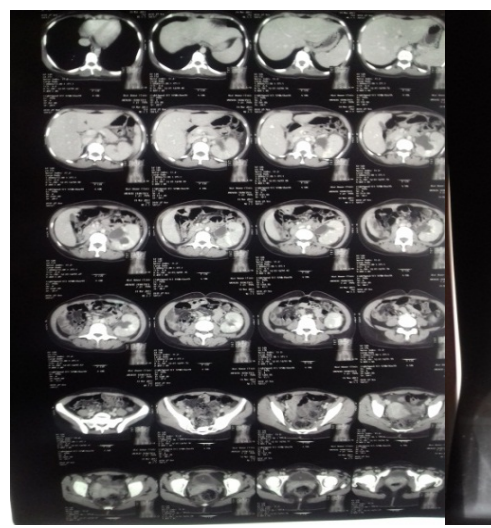

(a)

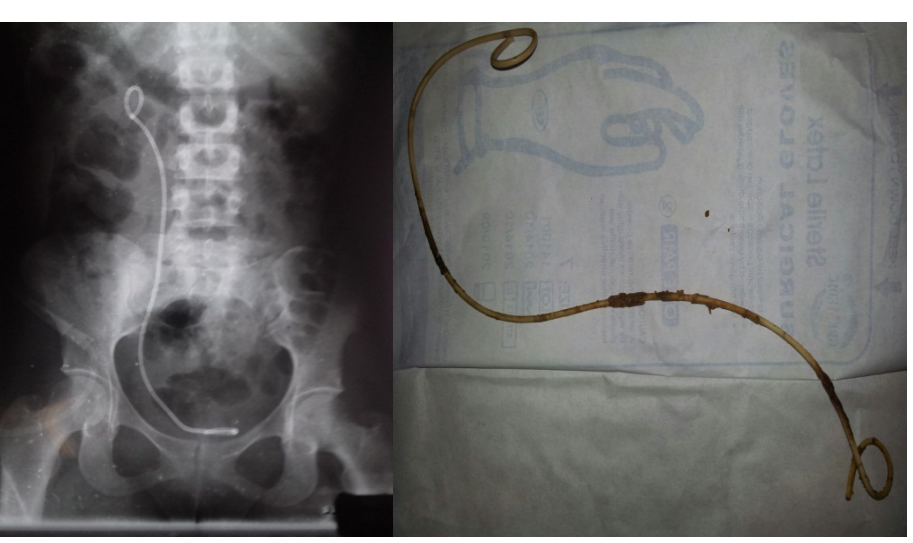

(b)

(c)

Figure 3. Images of the Forgotten Ureteric stent in case 3.

malignant ureteral obstruction (MUO). The metallic stents currently available are namely, self-expandable, balloon expandable, covered and thermo-expandable shape memory stents [15]. Silver and diamond-like carbon coatings are effective strategy to reduce biofilm adherence due to their wide-spectrum antimicrobial ability and excellent biocompatibility respectively [16] [17]. Stents coated with polymers such as pentosan polysulfate, phosphorylcholine copolymer and polyvinylpyrollidone provide excellent lubricant properties enhanced biocompatibility and reduced encrustation. Also newer drug eluting stents (DES) incorporate antibiotic into their biodegradable coating, thus modulating their pharmacokinetics to induce a stable and long-term release of the drug [15] [18] [19]. Novel modifications in stent design and material continue to be made to reduce stent encrustations.

Stent breakage is sometimes associated with encrustation in forgotten stents as was seen in the second patient. Stents may also fracture spontaneously (as in case 2) after being in situ for a long time due to hardening and loss of tensile strength [1] [20]. Most studies showed a predominance of encrustation at the upper coil of the stent. This may be because more effective peristalsis at the lower part of the stent sweeps any deposits off the stent, thus minimizing encrustation at the lower end [3]. Our patient in case 1 however, had heavy stone burden at bladder coil (Figure 1(b)).

The site of encrustation, the size of the stone burden and the function of the affected kidney dictates the method of treatment. Management of encrusted ureteral stents as occurs in forgotten stents often requires multiple endourologic approaches and/or open surgeries.

For encrustations located at the upper coil and or stent body, ESWL and flexible ureteroscopy retrieval of the stent has been reported to be non-invasive and effective first line therapy. The shock waves can be directed at the proximal or ureteral part of the encrusted stent under fluoroscopic guidance. ESWL is however indicated 
mainly for localized, low volume encrustations [21]-[23].

Ureteroscopy using ultrasonic lithotripsy may also be attempted, either as first-line therapy or after failure of ESWL. Flexible ureteroscopy with holmium laser lithotripsy is an alternative minimally invasive treatment option. More invasive procedures, such as PCNL or open pyelolithotomy are often necessary for treating a severely encrusted stent [21] [24]-[26].

Endourological approaches have been noted to be safe and mostly successful [3]. In our series, the patients were discharged 2 days after the endoscopic procedures and quickly resume to their usual daily activities but the second case which had an unsuccessful open pyelolithotomy was discharged 7 days after surgery. All 3 (100\%) cases in our series, also in Okeke et al. [27] and Papoola et al. [28] eventually underwent successful endoscopic retrieval of the stent material with no complications. The use of laser, saline irrigation fluid and ureteral stent added an extra cost of approximately 1000 USD in the endourology group. However, the cost for shorter hospitalization, no wound care, cosmesis and quick return to work in the endourology group may perhaps makeup for the difference in the cost of surgery in these two groups.

Kane et al. in Senegal reported their experience in a comparative study of 89 patients with upper urinary tract calculi who underwent endourology intervention or open surgery. Less complication and early discharge from hospital was observed in the endourology group [29].

Despite these observed advantages with these minimally invasive techniques, there is widespread lack of well-established endourology in the West Africa sub-region. A report by Ramyil et al. on their management of upper urinary tract obstructions indicated their use of open surgeries due to the absence of modern facilities thus subjecting all their patients to open procedure [30].

Shaibu et al. in 2013 reviewed log books of final year Urological residents presented for the West African College of Surgeons (WACS) and National Postgraduate Medical College (NPMC) final part II exams from January 2007 to December 2011 at Jos University Teaching Hospital (JUTH), Nigeria. They concluded that there was a decline in endoscopic surgeries despite overall increase in absolute number of operative cases performed by final year residents in the period after the commencement of the Urology residency programme [26].

A tabulation of our findings from a search of English publication on endourological procedures in the sub region (Table 1) confirmed the paucity of endourological procedures for the treatment of upper urinary tract pathologies in the West African sub-region. This calls for efforts at training and increasing access to endourology equipment and services to improve the management of upper urinary pathologies including calculi as occurs in the cases of forgotten ureteral stents [31]-[34].

Although encrusted stents can be managed successfully in the majority of cases, the best treatment is prevention. Urology units should have preferably an electronic stent register such that when the time for removal is due, the patient name and details are flagged red. If electronic register is not available, then a hard paper/book register should be made to prevent situations of forgotten stents. Information leaflets should be made by departments on post-operative complications, need for removal and date of removal of indwelling stents. Copies could be given to parents or spouses.

\section{Conclusion}

Forgotten ureteral stent is an uncommon finding in our center. The availability of endourological equipment facilitated the retrieval of the encrusted stents even when open surgery was not successful. Efforts must be made to improve endourological service in the West Africa sub-region to allow patients to have the benefit of endourology in the management of upper urinary tract pathologies including that of stones originating from an encrusted or fractured forgotten stent.

\section{Informed Consent}

Informed consent was obtained from all 3 patients in our series.

\section{Conflict of Interest}

None declared.

\section{Acknowledgements}

The authors would like to thank the patients for their invaluable support and willingness to volunteer vital 
Table 1. Summary of some publications on endourological interventions in West Africa.

\begin{tabular}{|c|c|c|c|c|c|c|c|c|c|c|c|}
\hline No & Author & Country & Year & $\begin{array}{l}\text { Sample } \\
\text { size }\end{array}$ & Subject/Interest & $\begin{array}{l}\text { Lower } \\
\text { urinary } \\
\text { tract }\end{array}$ & $\begin{array}{l}\text { Upper } \\
\text { urinary } \\
\text { tract }\end{array}$ & Outcomes & & & \\
\hline & & & & & & $\begin{array}{l}\text { Open } \\
\text { surgery }\end{array}$ & $\begin{array}{c}\text { Endoscopic } \\
\text { cases }\end{array}$ & $\begin{array}{c}\text { Open } \\
\text { surgery }\end{array}$ & $\begin{array}{l}\text { Endoscopic } \\
\text { cases }\end{array}$ & Open & Endoscopic \\
\hline 1 & Akporiaye & Nigeria & 2004 & 27 & $\begin{array}{l}\text { Transurethral } \\
\text { vaporisation of } \\
\text { the prostate }\end{array}$ & NA & 27 & NA & NA & NA & 27 \\
\hline 2 & L.I. Okeke. & Nigeria & 2004 & 10 & TURP & NA & 10 & NA & NA & NA & $\begin{array}{c}(10) \\
100 \%\end{array}$ \\
\hline 3. & $\begin{array}{l}\text { A. A. Salako } \\
\text { et al. }\end{array}$ & Nigeria & 2005 & 51 & $\begin{array}{l}\text { Endourology in } \\
\text { a Nigerian } \\
\text { Hospital }\end{array}$ & NS & $\begin{array}{l}20 \% \text { of all } \\
\text { cases }\end{array}$ & NS & Nil & NS & $20 \%$ \\
\hline 4. & $\begin{array}{l}\text { V.M. Ramyil et } \\
\text { al. }\end{array}$ & Nigeria & 2005 & $\begin{array}{c}37 \\
(2-N T)\end{array}$ & UUTO & NIL & NS & 29 (83\%) & NS & $\begin{array}{l}(29) \\
\mathbf{8 3} \%\end{array}$ & NS \\
\hline 5 & Kyei et al. & Ghana & 2012 & 58 & $\mathrm{BPH}$ & $79.3 \%$ & $20.7 \%$ & NA & NA & $79.3 \%$ & $20.7 \%$ \\
\hline 6 & $\begin{array}{c}\text { A.A. Popoola et } \\
\text { al. }\end{array}$ & Nigeria & 2013 & 39 & OFU & NA & 39 & NA & NA & NA & $\begin{array}{c}(39) \\
100 \%\end{array}$ \\
\hline 7 & $\begin{array}{l}\text { O.I. Aisuodionoe- } \\
\text { Shadracha et al. }\end{array}$ & Nigeria & 2013 & 57 & TURP-TUVP & NA & 57 & NA & NA & NA & $\begin{array}{c}57 \\
(\mathbf{1 0 0} \%)\end{array}$ \\
\hline 8 & R. Kane et al. & Senegal & 2015 & 89 & $\begin{array}{l}\text { Open versus } \\
\text { endoscopy }\end{array}$ & NA & NA & $\begin{array}{c}42 \\
(47.2 \%)\end{array}$ & $\begin{array}{c}47 \\
(52.8 \%)\end{array}$ & $\begin{array}{c}(42) \\
47.2 \%\end{array}$ & $\begin{array}{c}(47) \\
(52.8 \%)\end{array}$ \\
\hline 9 & Bray et al. & Ghana & 2016 & 3 & $\begin{array}{l}\text { Forgotten ureteral } \\
\text { stents in a } \\
\text { Tertiary Hospital } \\
\text { in Accra }\end{array}$ & NA & NA & 1 & 2 & $\begin{array}{l}(0) \\
\mathbf{0 \%}\end{array}$ & $\begin{array}{c}(3) \\
100 \%\end{array}$ \\
\hline
\end{tabular}

Key: NS—Not Stated, NA-Not Applicable, NT—Not Treated, BPH-Benign Prostate Hyperplasia, OFU—Outpatient Flexible Urethroscopy, UUTO-Upper Urinary Tract Obstruction, TURP—Transurethral resection of the prostate, TUVP_Transurethral vaporization of the prostate.

information needed for this publication.

\section{References}

[1] Zimskind, P.D., Fetter, T.R. and Wilkerson, J.L. (1967) Use of Long-Term Indwelling Silicone Rubber Ureteral Splints Inserted Cystoscopically. The Journal of Urology, 97, 840.

[2] Fishman, J.R. and Presto, A.J. (1994) The Forgotten Ureteral Stents, Alerts, Notices and Case Reports, WJM, 570, 160-166.

[3] Dakkak, Y., Juanane, A., Ould-Ismail, T., et al. (2012) Management of Encrusted Ureteral Stents. African Journal of Urology, 18, 131-134.

[4] Singh, I., Gupta, N.P., Hemal, A.K., et al. (2001) Severely Encrusted Polyurethane Ureteral Stents-Management and Analysis of Potential Risk Factors. Urology, 58, 526-31.

[5] Keane, P.F., Bonner, M.C., Johnson, S.R., et al. (1994) Characterisation of Biofilm and Encrustation on Ureteric Stents in Vivo. British Journal of Urology, 73, 687-691.

[6] Desgrandchamps, F., Moulinier, F., Daudon, M., et al. (1997) An in Vitro Comparison of Urease-Induced Encrustation of JJ Stents in Human Urine. British Journal of Urology, 79, 24-27.

[7] Murthy, K.V.R., Reddy, S.J. and Prasad, D.V. (2010) Endourological Management of Forgotten Encrusted Ureteral Stents. International Brazilian Journal of Urology, 36, 420-429.

[8] Robert, M., Boularan, A.M., El Sandid, et al. (1997) Double J Ureteric Stent Encrustations: Clinical Study on Crystal Formation on Polyurethane Stents. Urology International, 58, 100-103.

[9] Ramyil, V.M., Dakum, N.K., Ogwuche, E.I. (2006) The Management of Upper Urinary Tract Obstruction in ResourcePoor Settings. African Journal of Urology, 13, 1110-5704.

[10] Fiuk, J., Bao, Y., Calleary, J.G., et al. (2015) The Use of Internal Stents in Chronic Ureteral Obstruction. The Journal of Urology, 193, 1092-1099. 
[11] El-Faqih, S.R., Shamsuddin, A.B., Chakrabarti, A., et al. (1991) Polyurethane Internal Ureteric Stents in Treatment of Stone Patients; Morbidity Related to Indwelling Times. Journal of Urology, 146, 1487-1491.

[12] Auge, B.K., Ferraro, R.F., Madenjian, A.R., et al. (2002) Evaluation of a Dissolvable Ureteral Drainage Stent in a Swine Model. The Journal of Urology, 168, 808-812.

[13] Cauda, F., Cauda, V., Fiori, C., et al. (2008) Heparin Coating on Ureteral Double J Stents Prevents Encrustations: An in Vivo Case Study. Journal of Endourology, 22, 465.

[14] John, T., Rajpurkar, A., Smith, G., et al. (2007) Antibiotic Pretreatment of Hydrogel Ureteral Stent. Journal of Endourology, 21, 1211.

[15] Chung, H.H., Lee, S.H., Cho, S.B., et al. (2008) Comparison of a New Polytetrafluoroethylene-Covered Metallic Stent to a Noncovered Stent in Canine Ureters. CardioVascular and Interventional Radiology, 31, 619.

[16] Pechey, A., Elwood, C.N., Wignall, G.R., et al. (2009) Anti-Adhesive Coating and Clearance of Device Associated Uropathogenic Escherichia Coli Cystitis. The Journal of Urology, 182, 1628-1636.

[17] Laube, N., Kleinen, L., Bradenahl, J. and Meissner, A. (2007) Diamond-Like Carbon Coatings on Ureteral Stents-A New Strategy for Decreasing the Formation of Crystalline Bacterial Biofilms? The Journal of Urology, 177, 19231927.

[18] Chew, B.H., Davoudi, H., Li, J. and Denstedt, J.D. (2010) An in Vivo Porcine Evaluation of the Safety, Bioavailability and Tissue Penetration of a Ketorolac Drug-Eluting Ureteral Stent Designed to Improve Comfort. Journal of Endourology, 24, 1023-1029.

[19] Krambeck, A.E., Walsh, R.S., Denstedt, J.D., et al. (2010) A Novel Drug Eluting Ureteral Stent: A Prospective, Randomized, Multicenter Clinical Trial to Evaluate the Safety and Effectiveness of a Ketorolac Loaded Ureteral Stent. The Journal of Urology, 183, 1037-1043.

[20] Mursi, K., Fayad, A., Ghoneim, I. and El-Ghamrawy, H. (2005) Stones on a Forgotten Double-J Stent: A Case Report of Multiple Stones Casting a Multi-Fracture Ureteral Stent. African Journal of Urology, 11, 247-249.

[21] Somers, W.J. (1996) Management of Forgotten or Retained Indwelling Ureteral Stents. Urology, 47, 431-435.

[22] Vanderbrink, B.A., Rastinehad, A.R., Ost, M.C. and Smith, A.D. (2008) Encrusted Urinary Stents: Evaluation and Endourologic Management. Journal of Endourology, 22, 905-912.

[23] Aravantinos, E., Gravas, S. and Karatzas, A.D. (2006) Forgotten, Encrusted Ureteral Stents: A Challenging Problem with an Endourologic Solution. Journal of Endourology, 20, 1045-1049.

[24] Mohan-Pillai, K., Keeley Jr., F.X., Moussa, S.A., Smith, G. and Tolley, D.A. (1999) Endourological Management of Severely Encrusted Ureteral Stents. Journal of Endourology, 13, 377-379.

[25] Bukkapatnam, R., Seigne, J. and Helal, M. (2003) 1-Step Removal of Encrusted Retained Ureteral Stents. Journal of Urology, 170, 1111-1114.

[26] Shuáibu, S.I., Ramyil, V.M. and Dakum, N.K. (2013) Has the Creation of a Urology Residency Programme Translated in to More Surgical Exposure for Final Year Residents? Nigerian Medical Journal, 22, 57-60.

[27] Okeke, L.I. (2004) Day Case Transurethral Prostatectomy in Nigeria. West African Journal of Medicine, 23, 128-130.

[28] Popoola, A.A., Abiola, O.O., Arogundade, A.K. and Buhari, T. (2013) Outpatient Flexible Urethroscopy-Initial Experience at University of Ilorin Teaching. Journal of the West African College of Surgeons, 3, 63-74.

[29] Akporiaye, L.E. (2004) Early Results of Transurethral Vaporisation of Prostate in Nigeria. West African Journal of Medicine, 23, 139-141.

[30] Ramyil, V.N., Dakum, N.K. and Ogwuche, E.I. (2006) The Management of Upper Urinary Tract Obstruction in Resource-Poor Settings. African Journal of Urology, 13, 30-36.

[31] Salako, A.A., Badmus, T.A., Sowande, O.A., Adeyemi, B.A., Nasir, A.A. and Adejuyigbe, O. (2005) Endourology in a Nigerian Tertiary Hospital-Current Level of Practice and Challenges. Nigerian Journal of Surgical Research, 7, 268270.

[32] Kyei, M.Y., Mensah, J.E., Morton, B., et al. (2012) Surgical Management of BPH in Ghana: A Need to Improve Access to Transurethral Resection of the Prostate. East African Medical Journal, 89, 241-245.

[33] Aisuodionoe-Shadracha, O.I. and Akporiaye, L.E. (2013) Outcome of the TURP-TUVP Sandwich Procedure for Minimally Invasive Surgical Treatment of Benign Prostatic Hyperplasia with Volume Larger than 40cc over a 4-Year Period in Nigeria. African Journal of Urology, 19, 22-25.

[34] Kane, R., Diallo, Y., Niang, L., et al. (2015) Upper Urinary Tract Calculi in Senegal: A Comparative Study between Open Surgery and Endoscopy, a Review of 89 Cases. Open Journal of Urology, 5, 142-146. 